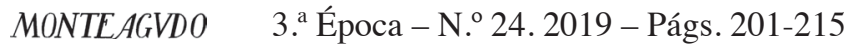

\title{
Reformarse es Vivir. Los Motivos de Proteo DE José ENRIQUE Rodó y LA TRAdICIÓN CLÁSICA DE LOS EJERCICIOS FILOSÓFICO-LITERARIOS
}

\author{
Bernat Castany Prado \\ Universidad de Barcelona
}

\section{RESUMEN:}

El objetivo de este artículo es estudiar la influencia de la tradición clásica de los ejercicios filosófico-literarios en Motivos de Proteo (1909), de José Enrique Rodó. Centrándome en las coincidencias existentes entre el ensayo de Rodó y las obras de autores como Marco Aurelio, Erasmo o Montaigne, analizaré algunos de los aspectos principales de dicha tradición, como son las ideas de «conversión», «salvación», «disciplina», «regla de vida» o «ejercitación» filosóficas.

\section{PALABRAS CLAVE:}

José Enrique Rodó. - Ensayo latinoamericano. Literatura y filosofía. - Ejercicios espirituales.

\begin{abstract}
:
The objective of this article is to study the influence of the classical tradition of the philosophicalliterary exercises on Motivos de Proteo (1909), by José Enrique Rodó. Focusing in the coincidences between Rodo's essay and the works of authors such as Marcus Aurelius, Erasmus or Montaigne, I will analyze some of the main aspects of this tradition, such as the ideas of «conversion», «salvation», «discipline», «rule life» or «exercise» in a philosophical sense.
\end{abstract}

KEYWORDS:

José Enrique Rodó. - Latin American essay. - Literature and philosophy. - Spiritual Exercises..

\section{I}

José Enrique Rodó, que llegó a afirmar en su Ariel (1900) que Grecia fue «la más genial y civilizadora de las razas» (1985: 199), es, quizás, el escritor latinoamericano al que mejor se aplica el célebre dictum borgeano de que «somos irreparablemente griegos». También fueron griegos irreparables el romano Marco Aurelio, quien llegó a escribir en griego sus Meditaciones y el francés Michel de Montaigne, quien pensó sus Ensayos en latín, que era su verdadera primera lengua, ya que su padre lo había educado siguiendo al pie de la letra el Plan de estudios (1511) concebido por otro griego vocacional como fue Erasmo. 
Podríamos agregar muchos otros nombres a esta acrópolis eterna, desde los padres del cristianismo occidental y oriental, hasta Marguerite Yourcenar, y sus Memorias de Adriano, o Virginia Woolf, y su «De la importancia de no saber griego», pasando por Goethe, quien, en sus Urworte o Palabras originarias, llegará a concebir la vida como un rendir cuenta a cinco divinidades griegas: el Daimon (guía interior), la Tyché (fortuna), el Eros (amor), la Ananké (necesidad) y la Elpis (esperanza). Añádanse, entre otros, a Emerson, Thoreau o Whitman, que trataron de llevar una vida filosófica, al modo de «los filósofos más ilustres» de Diógenes Laercio; Nietzsche, que se propuso recuperar la filosofía pagana puenteando al cristianismo; Heidegger, que vio en los presocráticos un modo más auténtico de pensar; o Arendt, que admiró la concepción griega de la acción.

En este trabajo voy a centrarme en la relación entre los Motivos de Proteo (1909) de José Enrique Rodó y las Meditaciones de Marco Aurelio, los Apotegmas de Erasmo, los Ensayos de Montaigne. De un lado, me ocupo de Motivos de Proteo, porque coincido con Benedetti en que es «la obra fundamental de Rodó» (1966: 57), así como de buena parte de la intelectualidad uruguaya y latinoamericana de principios de siglo. Del otro lado, comparo la obra de Rodó con las de Marco Aurelio, Erasmo y Montaigne, en primer lugar, porque me parece evidente que beben de un mismo acervo de ideas y prácticas filosóficas de origen grecolatino, y, en segundo lugar, porque cubren las tres etapas históricas fundamentales de las relaciones entre la filosofía occidental y la religión cristiana: Marco Aurelio es anterior a la hegemonía espiritual cristiana; Erasmo y Montaigne son cristianos, si bien proponen una inflexión grecolatina de dicha religión; y Rodó es, aunque de un modo menos radical y enfático que Nietzsche, pagano o poscristiano.

Mi intención no es, en absoluto, oponer la filosofía y la religión al modo en que lo hizo, por ejemplo, Marcel Conche, quien llegó a afirmar, en Ma vie antérieure, que «hay que escoger entre Atenas y Jerusalén» (1998: 85). ${ }^{1}$ De un lado, el cristianismo epicúreo de Erasmo y Montaigne muestra la posibilidad de una articulación equilibrada entre ambas sensibilidades; del otro, aunque el pensamiento de Rodó fue fundamentalmente secular, su actitud siempre fue conciliadora, tal y como puede comprobarse en los artículos que conforman Liberalismo y jacobinismo (1906).

Lo primero que llama la atención cuando comparamos a Rodó con Marco Aurelio, Erasmo y Montaigne es que, a pesar de que los cuatro insisten en que el mundo está en permanente transformación, sus escritos son la prueba de que hay algo que permanece a lo largo de los milenios. No me refiero aquí a la paradoja clásica de que el cambio permanece, sino más bien a un presupuesto fundamental, que podemos considerar como el acto de fe filosófica por excelencia, y que consiste en creer que

\footnotetext{
${ }^{1}$ «Car entre Athènes et Jérusalem, il faut choisir.» La traducción es nuestra.
} 
Reformarse es vivir. Los Motivos de Proteo de José Enrique Rodó y la tradición...

el ser humano es capaz de perfeccionarse a sí mismo. Puede parecer una obviedad, pero a veces es necesario seguir la metodología de Heidegger, quien, según Safranski, establecía «lo obvio de una forma que hasta los filósofos lo pudiesen captar». Ciertamente, sin esta creencia ninguno de estos cuatro autores habría gastado un solo minuto en escribir unos textos que proponen, precisamente, un plan de reforma filosófica, espiritual o existencial (no importa, quizás, el término, a condición de que seamos conscientes de que dicho proceso no afecta sólo al ámbito racional o al emocional, sino, como diría Machado, en su Juan de Mairena (1936), «al bloque psíquico completo»).

Esta convicción se expresa como dogma indubitable en las primeras palabras de Motivos de Proteo: «Reformarse es vivir» (\$ 1, pág. 63); y se hará patente a lo largo de todo el libro, ya sea implícitamente, pues cada una de sus palabras presuponen esa capacidad, ya sea explícitamente, como, por ejemplo, en el fragmento en el que Rodó se reafirma, ante la puerta de una cárcel, en su convencimiento de que todos, incluso los que están encerrados en esa prisión, tienen la capacidad de salvarse ( $§$ 141, págs. 289-291). ${ }^{2}$

Esta fe filosófica en la capacidad del ser humano para reformarse a sí mismo implica, a su vez, un ideal de reforma. No se trata, sin embargo, de una reforma religiosa, si bien existen numerosas semejanzas entre ambos procesos; no se trata tampoco de una mera reforma psicológica, como el mismo Rodó aclara al afirmar que su intención «no es escribir un libro de psicología», sino «un libro de 'geórgicas morales', de gimnástica del alma, de educación en el más amplio sentido». (folio suelto perteneciente probablemente a una carta a Unamuno de 1903-1904, cit. en Real de Azúa, 1985: XLI) ${ }^{3}$

Quizás el término «psicagogía» sea el que mejor se adapte al proyecto grecolatino, en general, y al rodoniano, en particular, pues su intención es, simple y llanamente, forjar un carácter, desde una perspectiva inmanente y racional. Eso es exactamente lo que afirma Rodó, en una carta dirigida a Unamuno, en 1904, donde sostiene que el tema fundamental de Motivos de Proteo es «la formación y el perfeccionamiento de la propia personalidad» (1967: 1393), para lo cual es necesario realizar una decisión fundante que él no duda en llamar «vía de conversión» (\$ 142, pág. 291).

\footnotetext{
2 «Si el azar le hubiera puesto frente a una casa que fuese presa del incendio, y hubiese visto, allá en lo alto, una mujer o un niño a punto de perecer entre las llamas, quizá un buen ángel le habría hablado al oído, y él se hubiera consgrado de héroe, y después de tal iniciación, perseveraría, probablemente en el bien, y suyas para siempre fueran la dignidad y la gloria.» (Rodó, Motivos de Proteo, § 141, pág. 290)

${ }^{3}$ Cabe decir que, en su carta del 12 de octubre de 1900, dirigida a Unamuno, Rodó sí afirmará que el tema de la transformación personal es una «cuestión psicológica».
} 
Lo cierto es que, tal y como nos informa el ensayo «Conversión», que el historiador de la filosofía antigua Pierre Hadot escribió para la Encyclopaedia Universalis, en la Antigüedad, el fenómeno de la conversión se daba «no tanto en el ámbito de lo religioso como en los órdenes político y filosófico». (2006a: 178) Siguiendo a Van der Leeuw, que consideraba que las religiones antiguas, salvo el budismo, son «religiones del equilibrio», en las que los ritos establecen una especie de economía de prestaciones (la adoración) y contraprestaciones (la protección) entre los hombres y los dioses, Hadot considera que las religiones de la antigüedad grecolatina «no reivindicaban para sí la totalidad de la vida interior de sus adeptos» (178). ${ }^{4}$ Quienes sí la reivindicaban, con sus proyectos y prácticas psicagógicas eran la filosofía y la política.

Bastará pensar en la filosofía platónica, que, tal y como se la expone en la República (518c), es fundamentalmente «una teoría de la conversión política» (Hadot, 2006a: 178); en los numerosos relatos de conversiones filosóficas (Pirrón, Crates, Hiparquia o Epicteto) que Diógenes Laercio recoge en sus Vidas de los filósofos más ilustres; o en un opúsculo como Filosofía de Nigrino, de Luciano de Samósata, en el que un joven narra, en términos que recuerdan mucho a la posterior mística cristiana, su conversión filosófica, tras haber escuchado las prédicas del filósofo, quizás ficticio, Nigrino.

La tradición de las conversiones filosóficas durará hasta nuestros días, alentada siempre por el ejemplo grecolatino y su recuperación humanística. Baste recordar los casos de Petrarca -cuya vida dará un giro radical tras el descubrimiento de las epístolas Ad familiares de Cicerón-; de Dante -cuya De vita nuova no apunta tanto a una conversión religiosa, como filosófica o artística-; de Montaigne, que se retiró del mundo a los 38 años, para llevar una vida filosófica, y cuyos Ensayos son a la tradición de las conversiones filosóficas, lo que las Confesiones de Agustín son a la tradición de las conversiones religiosas; de David Hume, que narra su conversión filosófica en su Autobiografía; o de Nietzsche, cuya visión en Sils-Maria supuso en él un cambio de vida radical.

En esta misma tradición se halla Rodó, quien, pensando en Dante, bautizó a uno de sus conjuntos de ensayos con el nombre La vida nueva, y que dedicará más de

\footnotetext{
${ }^{4}$ Ibídem, pág. 178. Esta distinción entre «religiones del equilibrio» y «religiones de la interioridad»se basa en la vieja distinción weberiana entre «religiones primitivas»-pragmáticas, mágicas, asistemáticas e indiferentes a perspectivas trascendentes-, y «religiones mundiales»-abstractas, sistemáticas y dispuestas a sacrificar los intereses inmediatos por la instauración de un nuevo mundo acorde a la idealidad trascendente-. Véase al respecto Hefner, Conversion to Christianity: Historical and Anthropological Perspectives on a Great Transformation, University of California Press, Berkeley, 1993, pág. 5 .
} 
Reformarse es vivir. Los Motivos de Proteo de José Enrique Rodó y la tradición...

una tercera parte de sus Motivos de Proteo a reflexionar sobre numerosos aspectos de la «conversión filosófica», como, por ejemplo, los estímulos que pueden propiciarla (los viajes en $\S 76$ y 88-97, la soledad en $\S 87$ o el amor en $\S 112-113$ ), el peligro de permanecer en el ámbito meramente teórico sin pasar a la práctica ( «Gran distancia va de convencido a convertido», $\S 138$, pág. 283, o las «tentaciones regresivas en la conversión incipiente», §142, pág. 291).

Cabe preguntarse, claro está, cuál es el ideal rodoniano al que tiende la conversión, que es el objeto de su inquebrantable fe filosófica, y que Rodó concibe como un ideal firme que sirva de «polo magnético» que oriente al espíritu gracias a «su virtud disciplinaria del alma» ( $\$ 111$, pág. 250). Podemos decir que dicho ideal es la «salvación», a condición de que, nuevamente, aclaremos que en el mundo grecolatino también existía una soteriología, o teoría de la salvación, filosófica.

Dicha salvación consistía en vivir de acuerdo con el summum bonum, que cada escuela filosófica definía en sus propios términos. Así, para los cínicos, la salvación era la autarkheia o libertad; para los epicúreos, la hedoné o placer, entendido como una «administración del goce» (según la formulación de Montaigne, en su ensayo «De la experiencia», III, xiii), que consiga que el saldo de placeres y displaceres, corporales y espirituales, fuese positivo; para los estoicos, la práctica de las aretai, virtudes o fortalezas, lo cual pasaba, a su vez, por vivir de acuerdo con la naturaleza; y para los escépticos, la ataraxia o serenidad, que se conseguía mediante la epoché o suspensión del juicio.

La soteriología filosófica que nos encontramos en Motivos de Proteo es ecléctica, como las de Marco Aurelio, Erasmo o Montaigne. En primer lugar, en la línea epicúrea, que incluiría, con diferencias de énfasis y de formulación, a Lucrecio, a Montaigne, a Spinoza e, incluso, a Nietzsche, Rodó considera que salvarse es lograr que los placeres, las pasiones alegres o la vida triunfen sobre los displaceres, las pasiones tristes o la muerte. Rodó considera que la «disciplina del corazón y la voluntad» debe buscar «alentar cuanto propenda a que extendamos a más ancho espacio nuestro amor, a nueva aptitud nuestra energía» (\$2, pág. 65), para lo cual, se debe luchar contra «las fuerzas que conspiren a retenerla [al alma] en un estado inferior, sea éste el sufrimiento, la culpa, la ignorancia, la esclavitud o el miedo». (\$ 149, pág. 301)

Es fundamental, al respecto, el penúltimo pasaje de Motivos de Proteo, en el cual se presenta como paradigma de lo que el mismo Rodó llama «pathos romántico» un cuadro otoñal, en el que «la apariencia triste y bella cobra el imperio de la realidad y nos persuade casi de la universal agonía de las cosas» ( $\$ 157$, pág. 312). Frente a esta tentación triste, Rodó afirma lo que podríamos llamar un «pathos clásico», esto es, grecolatino, que no acepta esa versión secular y esteticista del dolorismo cristiano, sino que busca siempre la afirmación de la vida: «No de otra manera, sobre el 
desconcierto de las hojas caídas se yergue la armazón escueta de los árboles, firme y desnuda como la certidumbre, y en el acero claro del aire graba una promesa, simple y breve, de nueva vida». (§ 157, pág. 312)

De un lado, el rechazo del dolorismo cristiano, en particular, y del antivitalismo platónico o idealista, en general, tan importante en Rodó, se da ya en Montaigne, quien afirma, en «De la experiencia», que acepta los placeres carnales como don divino, pues «oféndese a ese grande y todopoderoso donante, rechazando su don, anulándolo y desfigurándolo», ya que, según afirma Cicerón, «todo lo que es conforme a la naturaleza es digno de estima» (III, xiii, pág. 383); se da también en Spinoza, quien afirmará que «sólo una superstición triste y cruel puede prohibirnos la alegría» y «sólo una divinidad hostil podría alegrarse de mi debilidad y de mi sufrimiento, y honrar la virtud de mis lágrimas, de mis sollozos, de mis temores y de todas las cosas de este género» (Spinoza, Ética, libro IV, escolio de la proposición 45); y encuentra eco en Nietzche, quien considerará, en Ecce homo, que «el concepto de 'más allá', de 'mundo verdadero', fue inventado con el fin de desvalorizar el único mundo que existe» y el de 'alma inmortal' "para despreciar el cuerpo, enfermarlo -volverlo 'santo'-, para contraponer una espantosa despreocupación a todo lo que merece seriedad en la vida, a las cuestiones de la alimentación, vivienda, régimen intelectual asistencia a los enfermos, limpieza, clima». («Por qué soy un destino», § 8).

Del otro lado, la idea de administración sabia de los placeres y displaceres, que es uno de los temas fundamentales de Motivos de Proteo, forma parte de una larga tradición que, nuevamente, se remonta al concepto epicúreo de phrónesis, que será continuado, entre otros, por Montaigne, quien hablará de una «cierta administración en el goce», que exige que «la dulzura del contento y la prosperidad» se la deba «estudiar, saborear y rumiar» (III, xiii, pág. 381); por Spinoza, cuyos libros IV y V de su Ética quieren ser una sistematización de esta economía de los placeres y displaceres; por Nietzsche, quien pondrá a uno de sus libros el significativo título de Ciencia jovial; así como por un autor que Rodó admiraba, como es Walter Pater, quien no sólo escribió una novela de conversión, o Bildungsroman, como Mario el epicúreo (1885), sino que mantendrá ideas filosóficas inmanentistas afines a esta tradición, en general, y a la obra de Rodó, en particular: «La utilidad de la filosofía, de la cultura especulativa, para el espíritu humano, consiste en despabilarlo, en sobresaltarlo con una vida de constante y vehemente observación». (Pater, 1982: 181-182) ${ }^{5}$

Es interesante la idea de que Rodó quiere regresar desde un pathos romántico a un pathos clásico, puesto que Borges, que no admiró a Rodó, pero sí a Walter Pater,

\footnotetext{
${ }^{5}$ Han sido fundamentales para esta parte las reflexiones de Vicente Cervera Salinas en su ensayo «La poesía de la cultura: La esfera de Pascal, otro motivo de Proteo», incluido en Borges en la ciudad de los inmortales (2014: 132-163), donde señala la influencia de Walter Pater en Rodó y en Borges.
} 
Reformarse es vivir. Los Motivos de Proteo de José Enrique Rodó y la tradición...

como estudia Vicente Cervera Salinas, realizará un camino semejante, tal y como explica en su conferencia «Credo de poeta», donde afirma que, después de ser un joven «aficionado a la infelicidad», descubrió, hacia 1916, a Walt Whitman, hijo de Emerson, Spinoza y Montaigne, lo cual, dice, le hizo sentir «vergüenza de mi infelicidad». (2001a: 126-127) Cabe decir que Borges experimentó esta conversión salvífica del cuadro otoñal del pathos romántico a la «vida nueva» del pathos clásico, en 1916, poco después de la publicación de Motivos de Proteo, y apenas un año antes de la muerte de Rodó. ${ }^{6}$

La soteriología de Rodó adoptará también otra forma fundamental, como es la de la recuperación o el retorno, metanoia, al yo auténtico. No se trata sólo, pues, de adoptar un nuevo modo de vida en el que domine el placer y la alegría, sino también de recuperar el auténtico yo, tal y como sugieren el título del primero y del antepenúltimo capítulo de Motivos de Proteo: «Reformarse es vivir» (§ 1, pág. 64) y «Cambiar sin descaracterizarse» ( $\$ 156$, pág. 310). El mismo Rodó afirmará, en una carta dirigida a Unamuno, en 1904, que el tema de dicho ensayo «se relaciona con lo que podríamos llamar "la conquista de uno mismo"» (Obras completas, pág. 1393), y, en una carta a Alberto Nin Frías, que se ocupa de «la cultura del propio yo, [...] la formación de la personalidad, honda y firmemente desenvuelta mediante una incesante y orgánica renovación» (cit. en Real de Azúa, 1985: XLI).

Ese «uno mismo» no debe ser entendido en términos religiosos, pero tampoco psicoanalíticos, surrealistas o nacionalistas, sino, nuevamente, en términos griegos, pues hace referencia a la tradición grecolatina del daimon. Más allá de las interpretaciones trascendes del daimon, como una especie de genio tutelar o ángel de la guardia, dicha figura se nos representa, a través de la tradición que aquí contemplamos, como un proyecto existencial consistente en recuperar la mejor versión posible de uno mismo, el uno mismo verdadero. Así, desde el «llega a ser lo que eres», de Píndaro, hasta el subtítulo del Ecce homo, de Nietzsche, que reza «Cómo se llega a ser quien se es», existe toda una tradición daimónica que, a pesar de sus diferentes

\footnotetext{
${ }^{6}$ Cervera Salinas nos informa de que «a pesar de que Rodó fuese maestro de sus mejores maestros (mentor de Pedro Henríquez Ureña; inspirador del joven Alfonso Reyes)» fueron «pocas las citas y alusiones que recogiera Borges de los textos de Rodó.» (2014: 150) En efecto, Borges atacó a Rodó en un texto muy temprano, como es el «Prólogo» al Índice a la nueva poesía argentina (1926), del que renegó de algún modo, donde afirmó con dureza: «En cuanto a Rodó, fue un norteamericano, no un yanqui pero sí un catedrático de Boston, relleno de ilusiones sobre latinidad o hispanidad». Por otra parte, no sólo la figura de Proteo es habitual en la obra de Borges, sino también el método rodoniano -Cervera Salinas ve «La esfera de Pascal» como «un perfecto ejemplo de lo que José Enrique Rodó denominara "motivo de Proteo"». (Cervera Salinas, 2014: 151-153 y 147)-; sin contar la coincidencia en su escepticismo y en la concepción de la literatura como ejercicio espiritual.
} 
declinaciones, coincide en la idea central de que nuestra salvación filosófica, o existencial, depende de cuánto nos acerquemos a ese yo ideal.

Así, Sócrates describía a su daimon como «cierta voz que, cuando se deja escuchar, me aparta siempre de lo que iba a hacer» (Apología, 31 d); Platón, por su parte, utiliza la imagen del dios marino Glauco, cubierto de conchas, de algas y de guijas, para animarnos a descubrir bajo nuestras pasiones egoístas y ensimismadas el yo puro (República, 611d); Aristóteles lo hará coincidir con su concepto de «entelecheia», una naturaleza ideal a la que tendemos, y que poseemos desde el principio, independientemente de si se actualiza o no (De anima, II, 412, a27b1); Marco Aurelio considera que la filosofía «consiste en preservar el guía interior [daimon], exento de ultrajes y de daños». (II, 17, pág. 66); y Montaigne realizará todo un arte del «prestarse sin darse», una especie de filosofía de la «trastienda»o «l'arrière-boutique», que propugna el retiro del mundo para poder conservar intacto el propio yo: «Hemos de reservarnos una trastienda muy nuestra, libre, en la que establezcamos nuestra verdadera libertad y nuestro principal retiro y soledad». (I, xxxix, pág. 304) Los ejemplos son innumerables. Baste recordar, por ahora, la celda de Sor Juana Inés de la Cruz, la Habitación propia de Virginia Woolf o el «Retrato» de Antonio Machado:

Converso con el hombre que siempre va conmigo

-quien habla solo espera hablar a Dios un día-.

Mi soliloquio es plática con este buen amigo

que me enseñó el secreto de la filantropía.

(Campos de Castilla, XCVII, en Obras completas, t. II, pág. 491)

Cabe decir que Rodó no sólo conoce a Píndaro, a Nietzsche, a Montaigne y a Marco Aurelio, sino que también le dedica, en el libro V de sus Nuevos motivos de Proteo, una larga reflexión a lo que él llama el «estado Glauco», donde, además de asumir la imagen platónica, que ve a Glauco como el yo auténtico que hay que recobrar, y afirmar que toda la ansiedad de Pascal desaparece, «deja de pertenecerme», cuando Glauco retorna a su alma (Rodó, 1967: 976), trata de incorporar, influido quizás por Nietzsche o por el psicoanálisis, una concepción más trágica del yo:

No; no tienes tú toda la razón, ¡oh luminoso y sereno huésped mío, oh pagano que resucitas en mi alma!; iy aunque tu presencia me hace columbrar la gloria de los dioses, yo quiero que dejes lugar dentro de mí para las melancolías de que no sabes, para las inquietudes que no comprendes; para las fuentes de pensamiento y de amor que a ti te son desconocidas! (Rodó, 1967: 980) 
Reformarse es vivir. Los Motivos de Proteo de José Enrique Rodó y la tradición...

Es interesante notar los paralelismos entre este intento de síntesis de entre esta perspectiva atormentada y otra más armónica, como la que se halla al final de los Motivos de Proteo, y que busca un equilibrio entre un pathos romántico y otro clásico. Como señala Cervera Salinas, para Rodó, Pascal es emblema de la «fecundidad creadora del dolor» (2014: 145), aspecto en el cual se distancia de Borges, quien, en un ensayo como «Pascal», consideró al autor de los Pensamientos como «uno de los hombres más patéticos de la historia de Europa». (2001b: II, pág. 82)

Perfectamente inscrito en esta tradición, Rodó se representa el daimon como la voz auténtica que se ve siempre interrumpida o acallada por voces inauténticas: «Hay una misteriosa voz que, viniendo de lo hondo del alma, le anuncia, cuando no se confunde y desvanece entre el clamor de las voces exteriores, el sitio y la tarea que le están señalados en el orden del mundo». (\$ 40,pág. 108) Esta voz, a la que llamará también «vocación», no es descrita en términos trascendentes, como si fuese el alma de la persona del hombre o una voz angélica (si bien eso no impedirá que se la trate como algo sagrado), sino en términos inmanentes, pues la describirá más bien como «instinto personal» o «instinto de la vocación» (§ 40, pág. 110).

Rodó no sólo dedicará muchas páginas a reflexionar acerca de la buena voz, o vocación del yo auténtico o daimon, sino también acerca de las malas voces que nos distraen de aquello que nosotros mismos nos hemos llamado a ser. Marco Aurelio afirmó en sus Meditaciones, citando a Demócrito (fragmento 115 D): «El mundo, alteración; la vida, opinión» (IV, iv, pág. 83), lo cual nos recuerda directamente la insistencia rodoniana en el cambio y en el control de las voces interiores. La referencia a Marco Aurelio es importante, puesto que su libro es, en buena medida, un conjunto de ejercicios que buscan el control del discurso mental o hypolepsis, que, con su tendencia a sobreinterpretar y enjuiciar todo lo que nos sucede, añade un dolor innecesario al dolor estrictamente necesario, y reduce y bloquea los placeres de la existencia. ${ }^{7}$

Como vimos que sucedía con la idea de conversión y de salvación, la idea de «juicio erróneo», «pensamiento negativo» o logismós presente en el epicureísmo, el escepticismo o el estoicismo (Marco Aurelio, al que consideramos estoico, fue discípulo del mismísimo Sexto Empírico), fueron cristianizados bajo la forma de «pensamientos malignos» o «tentaciones demoníacas», en obras como Contra los

\footnotetext{
${ }^{7}$ De un lado, si me rompo una pierna hay un dolor necesario, que no puedo evitar, pero hay otro dolor innecesario, que surge de proyectar un juicio sobre esa situación, afirmando, por ejemplo, que «todo me sale mal» $\mathrm{o}$ «dios me ha castigado»; del otro lado, los juicios sobreañadidos acerca de los diferentes placeres, ya sea la idea de que son pecado, de que pronto se acabarán o de que otros pueden estar disfrutando placeres todavía mayores, tambien tiende a reducir o bloquear el placer que uno está, o podría estar, experimentando.
} 
pensamientos malignos (Antirrhetikos) o Acerca de los pensamientos malignos (Peri logismoi), ambas de Evagrio Póntico (s. IV d. C.), que proponen, bajo la forma de breves citas evangélicas, «respuestas» $\mathrm{O}$ «confutaciones» de las «voces», «pensamientos» o «tentaciones» de los demonios, con el objetivo de dejar el alma libre para el «coloquio de Dios» (2015: 7). Sin embargo, con Montaigne (que dice luchar y armarse para expulsar de sí «enojosos pensamientos» y «desagradables ideas»-«De la fisonomía», III, xii, pág. 303- con el objetivo de «de mantener en reposo mi alma y mis pensamientos»-en «De preservar la voluntad», III, x, pág. 275-), Pierre Charron (que, siguiendo a Montaigne, distinguirá entre pasiones fuertes y molestas, 1948, pág. 577), Spinoza (que sistematizará las pasiones tristes y alegres en los libros IV y V de su Ética, y propondrá una política al respecto en su Tratado teológico político) y Nietzsche (que hablará de pensamientos y sentimientos «venenosos y hostiles» en Del nacimiento de la tragedia), se recuperará la tradición secular de la lucha contra las voces o pensamientos perjudiciales para la felicidad y ocultadores del daimon. ${ }^{8}$

En esa misma tradición se inscribe Rodó cuando dedica los fragmentos 125 a 136 a reconocer y combatir las «Voces que se oponen a la emancipación de una conciencia» (§ 125, pág. 267). Según Rodó, son cuatro las «voces que te amilanan» y que «proceden, ya de boca de los otros, ya de lo interior de ti mismo» (§ 125, pág. 267). La primera es el orgullo ( $\$ 125)$, que nos impide cambiar; la segunda, el miedo a romper con nuestra educación (§ 126), contra la cual blandirá la hermosa evocación de «la despedida de Gorgias» (§ 127); la tercera, la melancolía (§ 133), que es una voz que «es triste y suave; y por suave y triste, poderosa», como, por ejemplo, la de la melancolía religiosa, contra la cual opondrá la idea de que lo más importante de la fe religiosa perdurará de algún modo en la fe secular: «Vestigio inmortal que deja de su paso toda fe sincera» (§ 134, pág. 278); y la cuarta, la que nos dice: «teme a la soledad, teme al desamparo» (§ 135, pág. 279), a la que opondrá «el poder de disciplina moral» (\$136, pág. 281).

Además de las contravoces o contraargumentos que propone para acallar las malas voces, o «logismoi», que surgen de nuestro discurso mental, o «hypolepsis», Rodó recomienda también el silencio: «Ayúdate de la soledad y del silencio!» (§ 121, pág. 264) Así, tras ponderar «cuán complejo problema es éste de nuestras relaciones con nuestro propio pensamiento!» ( $\$ 121$, pág. 263), Rodó propone recurrir a la soledad y el silencio de la noche, del campo o del mar, «donde no llegan miradas que te atemoricen o te burlen, ni hay otro dueño que la realidad de tu ser, superior a la jurisdicción de tu voluntad»; sólo así se podrá «discernir, dentro de la propia con-

\footnotetext{
${ }^{8}$ Algo semejante es lo que propugna actualmente la psicología cognitivo-conductual de Albert Ellis y Aaron Beck.
} 
Reformarse es vivir. Los Motivos de Proteo de José Enrique Rodó y la tradición...

ciencia, la idea que realmente vive, de la que, con semejanzas de vida, yace muerta» (\$121, pág. 263).

Hemos visto hasta aquí cómo Rodó comparte con el mundo grecolatino la fe en la capacidad de perfeccionamiento, que ha de tener lugar mediante una reforma o conversión, que busca, a su vez, una salvación filosófica o existencial, de corte laico, que puede consistir, tanto en el predominio de las pasiones alegres y la fuerza vital, como en la recuperación del yo auténtico o daimon. ${ }^{9}$

\section{II}

Cabe añadir que, en el mundo grecolatino, aquel que emprendía el camino de la filosofía solía adoptar una determinada regla de vida filosófica, que pautase y orientase el camino de su reforma. Como era de esperar, cada una de las escuelas filosóficas tenía su propia regla de vida. Sin embargo, la fagocitación de la idea de regla de vida por parte del cristianismo, y la demonización de buena parte de las antiguas escuelas filosóficas helenísticas, desorientaron al mismo Rodó, quien rechazará el escepticismo o el epicureísmo, sin darse cuenta de que en su época representaron reglas de vida muy semejantes a aquellas que él tratará de elaborar, de forma más o menos improvisada, en sus Motivos de Proteo.$^{10}$

Evidentemente, Rodó piensa en obras como los Pensamientos de Marco Aurelio, los Ensayos de Montaigne, los Hombres representativos de Emerson o el Ecce homo de Nietzsche. ${ }^{11}$ El autor de Ariel afirma la «necesidad de un principio director en el espíritu de cada uno de nosotros», que sea fuente «a un tiempo, de orden y de movimiento, de disciplina y de estimulación». (\$101, pág. 226-227) ${ }^{12}$

La regla de vida implicaba, claro está, una ejercitación o práctica espiritual o filosófica de las principales ideas o dogmas de la escuela escogida. Podemos considerar

\footnotetext{
${ }^{9}$ Para Erasmo la buena voz del daimon coincidía con la buena voz de los clásicos, que él trató de asimilar, en obras como Adagios y Apotegmas, mediante los dos maxilares de la «copia rerum» y la «copia verborum». De este modo, la captación de la voz de los clásicos resulta ser tanto un proyecto literario como un proyecto ético e, incluso, político.

${ }^{10}$ Dice por ejemplo que, «en el fuerte, la duda no es ni ocio epicúreo ni aflicción y desánimo» (§ 136, pág. 280), y habla «del escepticismo más helado y más yermo» (\$139, pág. 286), cuando él está asumiendo, claramente, muchas de las ideas y prácticas escépticas y epicúreas.

${ }^{11}$ Tampoco desecha la idea de una regla de vida colectiva, como puede verse en la siguiente cita: «¿Cuánto tiempo hace, quizá, que no te detienes a mirar frente a frente la idea a que te vincula una pasada elección; el dogma, la escuela o el partido, que da a tu pensamiento nombre público?» (§121, pág. 263).

${ }^{12}$ En esa misma época, Alain le dedicará uno de sus famosos Propos a la necesidad de adoptar una regla de vida filosófica: «Es necesario hacer un voto» (Alain, 2010: 251-253).
} 
que los términos «gimnástica del alma» o «geórgicas morales», con los que el mismo Rodó describiría sus Motivos de Proteo (cit. en Ottmar Ette, 2008: pág. 216), son traducción directa del término «askesis», o ejercicio, que se utilizaba en el mundo antiguo para referirse, no sólo a los ejercicios gimnásticos o escolares, sino también a los ejercicios espirituales filosóficos, tal y como los han estudiado autores como Alain (1906-1936), Pierre Hadot (2006b, 2009, 2013), el último Foucault (1981), Martha Nussbaum (2009) o Michel Onfray (2006).

Recordemos que, en la época Antigua, eran precisamente los ejercicios espirituales los que debían contribuir a generar o a mantener una vida filosófica. Siendo éstos muy variados, pues cada escuela y cada discípulo inventaba sus propios ejercicios, adaptando a sus objetivos un acervo común de prácticas filosóficas, es posible reconocer una estructura básica que tiende a repetirse. En general, la ejercitación filosófica suponía la condensación de una regla o norma de vida (kanon) en máximas y argumentos de carácter persuasivo (epilogismoi) que el discípulo debía aprender de memoria (mneme), meditar (melete) y ejercitar (askesis) con el objetivo de tenerlas siempre «a mano», transformadas en reflejos psicológicos o existenciales a los que recurrir de forma rápida e instintiva, en cualquier ocasión que pudiese presentársele (procheiron) (Hadot, 2006b: 28). ${ }^{13}$

Rodó se inscribe en esta tradición al presentar su libro como un conjunto de «ejercicios preparatorios» ( 3 , pág. 67), que buscan trabajar «la disciplina del corazón y la voluntad» (\$2, pág. 66). No es extraño, pues, que, aunque sea inconscientemente, practique todas y cada una de las modalidades de ejercicios espirituales grecolatinos.

En primer lugar, Rodó trata de condensar en su libro su propia regla o norma de vida filosófica (kanon), con el objetivo de tenerla siempre a mano (procheiron), al modo del viejo género de los manuales (enquiridion), como, por ejemplo, los de Epicteto o Erasmo. La vocación práctica del libro se nos revela en que éste no adopta la forma del tratado frío y sistemático, sino que busca acuñar máximas y argumentos de carácter persuasivo (epilogismoi), como puede comprobarse en la misma estructura del libro, ya que el título de cada capítulo busca ser una máxima que el cuerpo del capítulo busca iluminar e incorporar mediante el comentario, al modo de los Adagios y Apotegmas de Erasmo.

Además de estas máximas, Rodó utiliza, con una función tanto ilustradora como práctica, las parábolas -aunque no tanto como prometía el epígrafe, que rezaba «Todo se trata por parábolas» (San Marcos)-, que no es sólo una tradición evangélica y oriental, sino también grecolatina; las biografías, al modo de las Vidas de filósofos más ilustres de Diógenes Laercio; y las anécdotas filosóficas, al modo de las chreiai cínicas o escépticas. Además del uso de estos géneros filosófico-literarios,

\footnotetext{
${ }^{13}$ Véase también Castany Prado (2017: 261-274).
} 
Reformarse es vivir. Los Motivos de Proteo de José Enrique Rodó y la tradición...

existe en Rodó una vocación estética general, que tiene también una función persuasiva, tal y como él mismo indica al afirmar que pretende «bañar» las ideas «con la luz de la imaginación y 'magnetizarla' con el prestigio hipnótico del estilo». (Rodó, 1920: 207)

Cabe señalar que Motivos de Proteo vacila entre el género de los manuales, de forma ordenada y sistemática, y el de las meditaciones escritas, o hypomnemata, que suelen adoptar una forma más desordenada y repetitiva, como sucede, por ejemplo, con las Meditaciones de Marco Aurelio, cuyo título original indica que eran «notas que se toman para uno mismo», esto es exhortaciones, recordatorios o prácticas imaginarias de los dogmas que formaban la regla de vida que había escogido (Hadot, 2009: 96)

Como las Meditaciones, los Motivos de Proteo adoptan, en parte, la forma de exhortaciones o ejercitaciones dirigidas a uno mismo, tà eis heautón, razón por la cual «lo importante no es tanto lo que [se] escribe como el hecho de escribirlo.» (Larrauri, 39) Según Ottmar Ette:

Desde el primer «motivo» se establece una relación directa entre el narrador y el público lector, entre un «yo» y un «tú». No obstante, estas dos voces, como en el modelo platónico, no llegan jamás a entablar un diálogo auténtico, porque las posturas del lector u oyente en general sirven como punto de partida para una conversación ficticia, que en el fondo es de naturaleza monológica. (2008: 212)

Esto explicaría que Rodó, tal y como explica en la «Nota inicial», diga de su obra que «nunca le daré "arquitectura" concreta, ni término forzoso: siempre podrá seguir desenvolviéndose, "viviendo"». (págs. 61-62)

Por esta razón, me parece que Alfonso Reyes se equivocó, en parte, cuando afirmó, en El suicida (1917), que el libro de Rodó, en tanto que «libro amorfo», «líquido» y «psicológico», es un libro moderno, que rompe con el libro clásico, que él entendía como una obra cerrada, sistemática y ordenada. Ciertamente, Motivos de Proteo presenta algunas de las principales características que asociamos a lo que Reyes llama «la literatura moderna», que luego se denominará posmoderna, pero también es cierto que, no sólo en él, sino también en otros autores, como Nietzsche, Bergson, Husserl o Heidegger, entre los filósofos, y Montaigne, Macedonio Fernández o Borges, entre los literatos, pueden ser consideradas como el resultado del proyecto de recuperación de las prácticas filosóficas grecolatinas.

En todo caso, esta ambivalencia entre el tratado y el género de las meditaciones o ejercicios espirituales explica que Motivos de Proteo pueda ser leído, por lo menos, de dos maneras. Acepta una lectura lineal, que actualizaría el tratado que contiene, y 
una lectura salteada, que correspondería, no tanto a un intento hermenéutico, como sí sucede en el caso de la ars virgiliana clásica o religiosa, o de la lectura adivinatoria de los códices precolombinos, como a un tipo de ejercitación. Ottmar Ette compara este doble modo de lectura con Rayuela (1963), de Julio Cortázar (2008: 218-219). El paralelismo no es baladí, puesto que, después de dicha novela, Cortázar dedicó buena parte de sus esfuerzos literarios a escribir toda una serie misceláneas que contenían ejercicios espirituales filosófico-literarios, como es el caso de Último round, La vuelta al día en ochenta mundos o Los autonoautas de la cosmopista.

Estudiosos como Carlos Real de Azúa (1985: LXII) y Ottmar Ette (2008: 219) han vinculado Motivos de Proteo a la tradición de la literatura de consejo, que consideran que aparece en la época moderna, a medida que la sociedad se seculariza y el fantasma del nihilismo empieza a amenzar occidente, pasando a «desempeñar en las sociedades laicizadas la vieja función que cumplían los manuales de meditación religiosa y, en un plano más social, la oratoria sagrada». (Real de Azúa, 1985: LXIII) Se equivoca, sin embargo, al considerar que estas obras de consejo, entre las que no sólo se cuentan los diálogos de Gourmont; Le trésor des humbles y La sagesse et la destinée de Maeterlinck, sino también los Ensayos de Montaigne, los escritos de Emerson, las Parerga y Paralipomena de Schopenhauer o las obras de Nietzsche, son «inofensivas usurpaciones» (LXIII). Lo cierto es que, como pretendo haber demostrado, fue la religión la que usurpó al mundo grecolatino todo ese acervo espiritual teórico-práctico.

Para acabar, señalemos que el término latino «conversio» corresponde a los términos griegos «episthrophe», o retorno, que implica la idea de renacimiento o regreso al origen, y «metanoia», o «cambio de pensamiento», que implica la renuncia a la existencia anterior, considerada inauténtica, y una transformación o renacimiento radical. En este sentido podemos afirmar que el Renacimiento fue una conversión al modo grecolatino de pensar y de vivir, un renacer como grecolatinos. Y no es casual que uno de las grandes influencias de Rodó sea Montaigne, que es la figura más importante de ese renacimiento filosófico-literario, o Walter Pater, que no sólo lo teorizó en obras como El Renacimiento, sino que también lo ficcionalizó en una obra como Mario el epicúreo (1885).

\section{Bibliografía}

Alain, Propos I et II, La Pléiade, Paris, 1956-1970 [1ª ed. 1906-1936].

Benedetti, Mario, Genio y figura de José Enrique Rodó, Buenos Aires, Editorial Universitaria, 1966.

Borges, Jorge Luis, Arte poética, Barcelona, Crítica, 2001a. 
Reformarse es vivir. Los Motivos de Proteo de José Enrique Rodó y la tradición...

-----, Obras completas, Barcelona, Emecé, 2001b.

Castany Prado, Bernat (2017): «La literatura y la tradición de los ejercicios espirituales filosóficos», Revista de filosofía, vol. 42, núm. 2, 2017, págs. 261-274.

Cervera Salinas, Vicente, «La poesía de la cultura: La esfera de Pascal, otro motivo de Proteo», en Borges en la ciudad de los inmortales, Sevilla, Renacimiento, 2014, págs. 132-163.

Conche, Marcel, Ma vie antérieure, Fougères, Encre Marine, 1998.

Charron, Pierre, De la sabiduría, Buenos Aires, Losada, 1948.

Ette, Ottmar, «Proteo en Uruguay», en Literatura en movimiento: espacio y dinámica de una escritura transgresora de fronteras en Europa y América, Madrid, CSIC, 2008, págs. 197-228.

Evagrio Póntico, Contra los pensamientos malignos (Antirrhetikos), Lima, Vida y espiritualidad, 2015.

Foucault, Michel, Tecnologías del yo, Barcelona, Paidós, 1990 [1 $1^{\text {a }}$ ed. 1981].

Hadot, Pierre, «Conversión», en Ejercicios espirituales y filosofía antigua, Madrid, Siruela, 2006a, págs. 177-188.

-----, Ejercicios espirituales y filosofía antigua, Madrid, Siruela, $2006 \mathrm{~b}$.

-----, La filosofía como forma de vida, Barcelona, Alpha Decay, 2009.

-----, La ciudadela interior, Barcelona, Alpha Decay, 2013.

Henríquez Ureña, Pedro, «La obra de José Enrique Rodó», en Conferencias del Ateneo de la Juventud, México D.F., UNAM, 1962, págs. 57-68.

Larrauri, Maite, El ejercicio según Marco Aurelio, Valencia, Tandem, 2009.

Machado, Antonio, Obras completas, IV tomos, Oreste Macrí (ed), Madrid, Espasa, 1989.

Nussbaum, Martha, La terapias del deseo. Teoría y práctica en la ética helenística, Barcelona, Paidós, 2009.

Onfray, Michel, Las sabidurías de la angitüedad, Anagrama, Barcelona, 2008 [1 ${ }^{\mathrm{a}}$ ed. 2006]

Pater, Walter, El Renacimiento, Barcelona, Icaria, 1982.

Real de Azúa, Carlos, «Prólogo a Motivos de Proteo», en José Enrique Rodó, Ariel. Motivos de Proteo, Caracas, Ayacucho, 1985, págs. XXXVII-XCV.

Rodó, José Enrique, Ariel. Motivos de Proteo, Ayacucho, Caracas, 1985.

-----, El que vendrá, Barcelona, 1920.

-----, Obras completas, Emir Rodríguez Monegal (ed.), Madrid, Aguilar, 1967.

-----, Proteo (Nuevos y Últimos motivos de Proteo), en Obras completas, Emir Rodríguez Monegal (ed,), Madrid, Aguilar, 1967, págs. 887-980.

Spinoza, Baruch, Ética, traducción de Oscar Cohan y estudio introductorio de Luciano Espinosa, Barcelona, Gredos-RBA, 2014. 